\title{
Experimental analysis of flexibility change with different levels of power reduction by demand response activation on thermostat controlled loads
}

\author{
Lakshmanan, Venkatachalam; Marinelli, Mattia; Hu, Junjie; Bindner, Henrik W.
}

Published in:

Electric Power Components and Systems

Link to article, DOI:

$10.1080 / 15325008.2016 .1232321$

Publication date:

2017

Document Version

Peer reviewed version

Link back to DTU Orbit

Citation (APA):

Lakshmanan, V., Marinelli, M., Hu, J., \& Bindner, H. W. (2017). Experimental analysis of flexibility change with different levels of power reduction by demand response activation on thermostat controlled loads. Electric Power Components and Systems, 45(1), 88-98. https://doi.org/10.1080/15325008.2016.1232321

\section{General rights}

Copyright and moral rights for the publications made accessible in the public portal are retained by the authors and/or other copyright owners and it is a condition of accessing publications that users recognise and abide by the legal requirements associated with these rights.

- Users may download and print one copy of any publication from the public portal for the purpose of private study or research.

- You may not further distribute the material or use it for any profit-making activity or commercial gain

- You may freely distribute the URL identifying the publication in the public portal 


\title{
Experimental analysis of flexibility change with different levels of power reduction by demand response activation on thermostat controlled loads
}

\author{
Venkatachalam Lakshmanan, Mattia Marinelli, Junjie Hu, Henrik W. Bindner \\ Centre for Electric Power and Energy, Technical University of Denmark, Risø campus, Roskilde, Denmark
}

\begin{abstract}
This paper studies the flexibility available with thermostatically controlled loads (TCLs) to provide power system services by demand response (DR) activation. Although the DR activation on TCLs can provide power system ancillary services, it is important to know how long such services can be provided for when different levels of power reduction are imposed. The flexibility change with different levels of power reduction is tested experimentally with domestic fridges used by real customers with unknown user interaction. The investigation quantifies the flexibility of household fridges and the impact of DR activation in terms of deviation in the average temperature. The maximum possible power reduction with the cluster of refrigerators is $67 \%$ and the available flexibility with the cluster of refrigerators is $10 \%$. The resulting deviation in the average temperature is $14 \%$.
\end{abstract}

Keywords: controllable load, demand response, demand side management, domestic energy resources, flexible electricity demands, smart grid.

*Corresponding author: Tel:004521 1243 41, Email address: vela@elektro.dtu.dk 


\section{Abbreviations}

BRP: Balance responsible party

COP: Coefficient of performance

DR: Demand response

ICT: Information and communications technology

QOS: Quality of service

RES: Renewable energy sources

TCL: Thermostatically controlled load

TSO: Transmission system operator

UFLS: Under-frequency load shedding

\section{Introduction}

The reliability of electric power system operation depends solely on the balance between power production and consumption. In a conventional power system, the balance is achieved by consumption-driven production. In such a scenario, long-term [1] and seasonal [2]load and change forecasting is used to plan new power plants and power production. As the electricity market has become unbundled, one-day-ahead demand forecasting helps to schedule the power procurement [3], [4]. The transmission system operator (TSO) is responsible for the power system balance. The errors in the demand forecast are managed by additional local procurement or consumption at short notice to avoid large deviations from the unit commitments of the power plants [5], [6]. Such services are called ancillary services and are provided by balance responsible parties (BRPs) and the regulating power providers on request from the power system operators. Due to increasing awareness of the negative environmental impacts of greenhouse gas emissions from conventional power plants' exhaust gasses, motivation for the usage of renewable energy resources (RESs) in the electric power system is high. Therefore, the participation and penetration of RESs increases as time goes on. The RES electricity 
supply varies, as RESs like wind and solar power fluctuate [7]. The fluctuations in the electric power production by RESs need to be compensated either by an additional supply of power from fossil based power plants [8], [9] or by controlling demand to achieve a balance in the power system[10]. Demand response (DR) is a widely accepted operational procedure carried out by power-system operators [11], [12].

Electricity consumers can be broadly classified into three classes: industrial, commercial, and domestic [13],[14]. The demand adjustment from industrial consumers is large in comparison to the other two segments [14]. Industrial consumers can support only a scheduled demand adjustment, as the machinery used may require a complex start-up and shutdown procedure and skilled manpower to execute the procedures. But the ancillary service requirement of demand adjustment may arise at anytime. Domestic and commercial consumers are suitable for ancillary service provision by DR due to their time availability and less complex electrical gadgets, which are easy to control.

In Nordic countries, the share of domestic electricity consumption is $26 \%[15]$ and the domestic segment has great potential for DR services[16]. During appliance control, the service provided by the appliance should not be affected by the control event. Such a constraint makes thermostatically controlled loads (TCLs) most suitable for DR applications. TCLs provide a temperature service. The temperature effect is stored in the thermal mass of the TCLs, which can sustain the impact of power reduction. In a single household, the flexibility for demand adjustment may be a small quantity. When the flexibility from multiple households is aggregated, their potential is very high. To manage the massive distributed TCLs, the aggregators can play an important role similar to the BRPs[17]. The aggregator may be a separate entity or a part of the BRP.

When the power system operator requires an ancillary service related to power reduction, the aggregator will serve the request by controlling the loads of the consumers. Under control, the service provided by the loads to the consumer should not be affected or the deviation in the quality of the 
service should be within the limits guaranteed to the consumers by the aggregator. The service provided by the TCLs is quantified in terms of temperature. Therefore, the deviations in the quality of service at different power-reduction levels can be analysed with the temperature variation. Also, the temperature of the TCL system represents the amount of thermal energy stored within the system, or in other words the flexibility available with the TCL. By predicting the temperature profile, the duration for which the system can support the service of power reduction can be predicted. Therefore, the variation in the available capacity with respect to different levels of power reduction can also be analysed. Further, the maximum possible power reduction by respecting the temperature limits of individual TCLs can be studied and the deviation in QOS can be analysed.

The aim of this work is to investigate the potential and capacity for power reduction by DR activation on TCLs using domestic refrigerators as an example. In Denmark, refrigerators and freezers contribute $18 \%$ of total domestic electricity demand and they are regarded as important DRs in the smart grid [18]. Refrigerators are considered for DR study in many research activities [19]-[21]. A simulation study with large-scale control of domestic refrigerators for reduction of peak demand in distribution systems is presented in [19]. In [20], a simulation study to support the primary reserve by underfrequency load shedding (UFLS) is studied. The energy consumption optimization of refrigerators is studied with a grey-box model developed using time series data from experimental measurements in [21].

The adaptive fridge model presented in [22] is used to predict the fridge behaviour for control purposes, as the model requires only two measurements and the prediction errors are within 5\% [23]. The investigations of the work presented in this paper consist in:

1. Real world application of refrigerator model.

A real world application for the black-box model described in [22] to provide power system service by load reduction is experimented. The black-box model requires only two measurements and predicts 
TCL temperature close to the actual one when the dynamics of the system are not changing. The model is a generalized model suitable for any type of TCLs. Such a model is suitable for experiments with a large number of TCLs, where the number of parameters measured is limited. The analysis reported in the paper under revision allowed evaluating the range of applicability of the model.

2. TCL control limitation due to resource synchronization.

The TCLs operation is synchronized when a group of TCLs is controlled for the aggregated power reduction. The higher is the aggregated power reduction the sooner will the TCLs operation get synchronised. The analysis presented in this paper defines the limits of the control method using the black-box model for aggregated power reduction without TCL operation synchronisation in terms of control duration.

3. TCL flexibility definition and evaluation.

The thermostatically controlled loads (TCL) are not available for power system service provision when the thermostat switched OFF the load. This paper defines the flexibility of the TCLs in such scenario without altering the TCL. A correlation between the available flexibility and the aggregated power is given under normal operation. The change in the flexibility of group of TCLs is analysed when the aggregated power is limited to different levels compared to the normal value. The flexibility analysis discussed in the paper can be used to derive a metric about the change in flexibility for a larger population of TCLs.

The rest of this paper is organized as follows. In Section 2 the method of flexibility analysis of power reduction with DR activation and the problem outline are introduced. Section 3 explains the experimental procedure, experiment platform, the hardware devices used for control and measurement, and their configuration. Section 4 discusses the control strategy and practical limitations in detail. The results of the experiments are reported in Section 5. The discussion and conclusion are presented in Sections 6 and 7 respectively. 


\section{Methodology}

The refrigerator is a thermally insulated box fitted with a compressor to pump heat out of the box to the ambient. The compressor is controlled by a thermostat. The temperature inside the refrigerator is maintained between two limits, namely Tmax and Tmin, by the thermostat. The thermostat switches the compressor $\mathrm{ON}$ when the temperature is above the temperature limit Tmax. The heat from the refrigerator is pumped out to the ambient by the refrigeration system. This causes the temperature inside the refrigerator chamber to decrease. As soon as the temperature decreases to the limit Tmin, the thermostat switches the compressor OFF. As the ambient temperature is higher than the temperature inside the refrigerator chamber, the heat flows from the ambient into the refrigerator cooling chamber through the walls and also during opening of the refrigerator door for food exchange. The heat flow causes the temperature of the cooling chamber to increase when the compressor is OFF. The heating and cooling cycles of the refrigerator can be called thermostatic cycles. The duration of the thermostatic cycle for heating and cooling depends on many parameters. The cooling duration required for the temperature to reach the value Tmin from the temperature value Tmax depends on the compressor power and its coefficient of performance (COP), the ambient temperature, the insulation parameters of the refrigerator, and the thermal properties of the cooling chamber's content (food). The duration of heating required for the temperature to rise from the value Tmin to Tmax depends on the parameters listed above, except for the compressor specifications. As the refrigerator has the ability to store the temperature effect with its thermal inertia, it can be used to provide the power system ancillary services. The method described here controls the refrigerators' state (ON/OFF) in order to keep their aggregated power consumption at a given set-point value without violating the temperature limits of the individual refrigerators. On controlling the refrigerator, one of the constraints is that the temperature Tmax of the refrigerator cool chamber should not be exceeded. The change in the available flexibility provided by the refrigerators can be analysed at different levels of power 
reduction from the normal consumption.

In the presented control architecture in Figure 1, a central controller for refrigerators collects the temperature measurements and power consumption from all refrigerators. The central controller can predict the temperature of fridges and the duration for which they can be switched OFF or ON without violating the temperature boundaries with the use of a simple black-box model [22]. The black-box model considers the temperature curves of the thermostatic cycles as a piece-wise linear one and uses the slopes of the temperature curves to predict the temperature cycle duration.

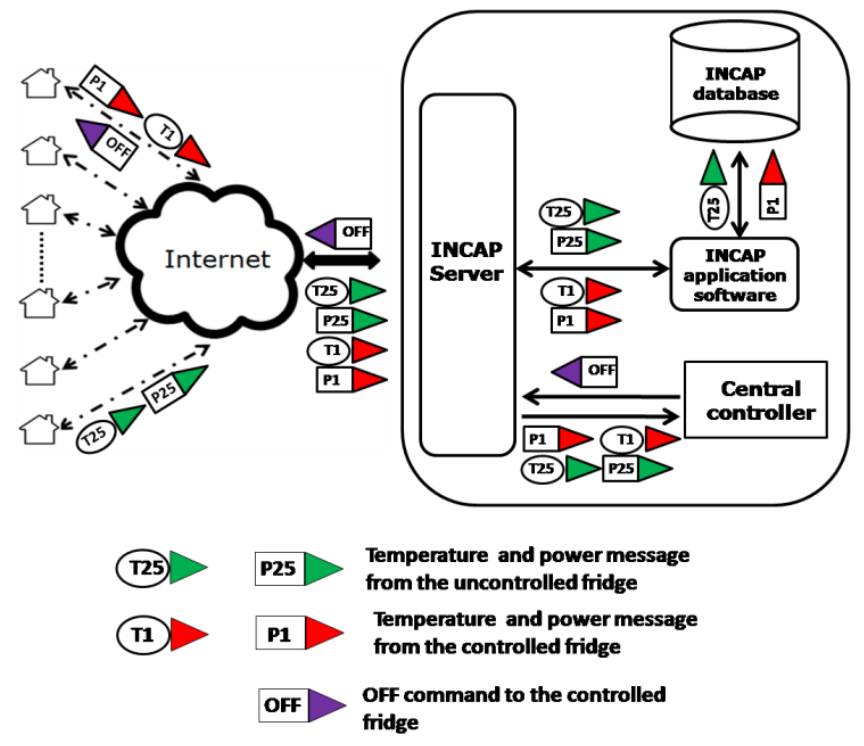

Figure 1. Control diagram and information flow.

In the proposed algorithm, the fridge flexibility is measured by the duration for which the refrigerator can be switched OFF without violating the individual refrigerator's temperature limit. The switch OFF time can be calculated by predicting the temperature inside the cooling chamber. In order to calculate the prediction of the cooling chamber temperature, the fridge's thermal behaviour has to be modelled. The black-box model [22] used in this study requires only two measurements and predicts a cooling chamber temperature close to the actual one when the dynamics of the system are not changing. It is also a generalized model suitable for any thermostatically controlled loads such as space heaters, heat pumps, air conditioners, refrigerators, and so on. Such a model is suitable for experiments with a large 
number of refrigerators, where the number of parameters measured is limited.

\section{Experimental procedure}

\subsection{Test scenarios}

The experiment is conducted for four scenarios with different values of power reduction as shown in the Figure 2.

Scenario 1: Scenario 1 is the base case without any control. The refrigerator power consumption and the temperature were observed for 24 hours. The observation without control gives an idea about the variation in aggregated power consumption with time. The power limitation setpoint for the control in the following scenarios is derived from the base case scenario 1 .

Scenario 2: In scenario 2, the control objective is to maintain the aggregated power at the average value of power consumption in scenario 1without violating the temperature limits of individual refrigerators.

Scenarios 3 and 4: Scenarios 3 and 4 are used to understand the limits of the possible power reduction by DR activation on TCLs. The power limits for the controller are set as 50 and $25 \%$ of scenario 1 average value in scenarios 3 and 4, respectively.

The proposed method for TCL flexibility analysis is tested with refrigerators in real households with unknown user interaction. The following section introduces the experimental set-up and provides a description of the information and communication technology (ICT) infrastructure supporting the experiment and a description of the gathered measurements.

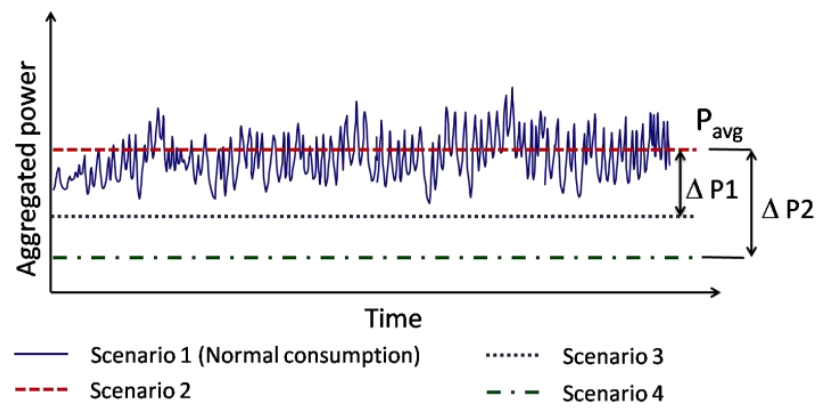


Figure 2. Scenario description.

\subsection{Experimental setup}

The experiment utilized the infrastructure and the refrigerators of the participants in the project INCAP. The INCAP project has established an ICT infrastructure for the real-time measurement and control of temperature and power of domestic fridges in the western part of Denmark for a field experiment. Figure 3(a) shows the experimental set-up. The block diagram in Figure 3(b)shows the devices installed for control and data collection in each household participating in the project INCAP. The devices used for control and data collection are as follows:

1. Relay unit with power measurement facility to switch the fridge ON and OFF in response to a remote command and to measure the active power consumption by the fridge.

2. Temperature sensor to measure the temperature inside the fridge cooling chamber.

3. A user interface device with red and green lights and two buttons to communicate with the user.

4. A Zigbee-Ethernet gateway device to enable interaction of these devices with the remote server.

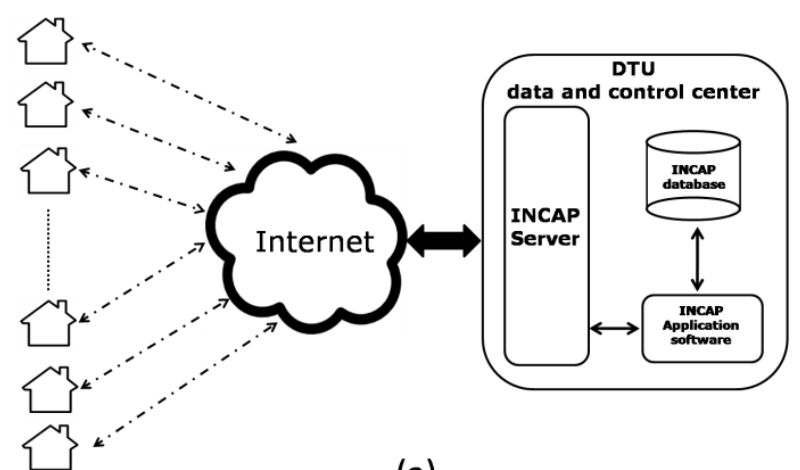

(a)

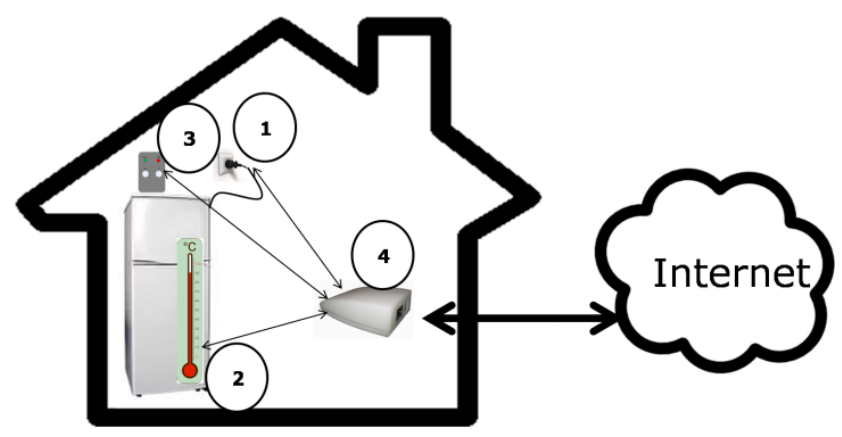

(b)

Figure 3. Data flow from the fridges to the controller and refrigerator control device installation in a 
house

Develco Products $\mathrm{A} / \mathrm{S}$, one of the partners in the project INCAP, provides these devices from its Zigbee wireless home automation network products line. The Zigbee-Ethernet gateway device hosts the local Zigbee home network as a coordinator, and other devices become the child of the local Zigbee network. The Zigbee-Ethernet gateway device establishes the connection to the control server through a wired ADSL home Internet connection. Two of the devices, namely the temperature sensor and the user interface device, are battery-powered devices, while the other two are mains supply powered. For the field experiment in INCAP, devices were sent to the consumers. Once installed, the devices sent authorization requests to the server and were authorized by the server to join the Zigbee network. The temperature sensor was placed in the cooling chamber of the fridge and the relay unit was connected in series with the power input to the fridge. The measurement sampling rates for the different devices were configured by the server.

\subsection{Measurement parameters and sampling rate}

The temperature sensor sends the temperature measurements at two-minute intervals. The sampling interval was preconfigured by the manufacturer in order to have a longer battery life. This sampling rate cannot be changed. As the temperature inside the refrigerator changes very slowly due to the thermal inertia of the food content, the two-minute sampling rate is sufficient to appreciate these dynamics. The temperature sensor has an accuracy of $\pm 0.5^{\circ} \mathrm{C}$. The relay unit measures the active power consumed by the fridge. The resolution of the measurement is $1 \mathrm{~W}$. The RMS voltage is also measured with $1 \mathrm{~V}$ accuracy. The measurement is taken every 10 seconds and sent to the server.

\section{Controller description}

\subsection{Controller architecture}

The controller has the following objectives: a) to predict the switch-OFF time of the fridges using the fridge model described in [22], and b) to limit the aggregated power consumption by controlling the 
fridges without violating their temperature limits. The controller execution is carried out according to the following Algorithm 1.

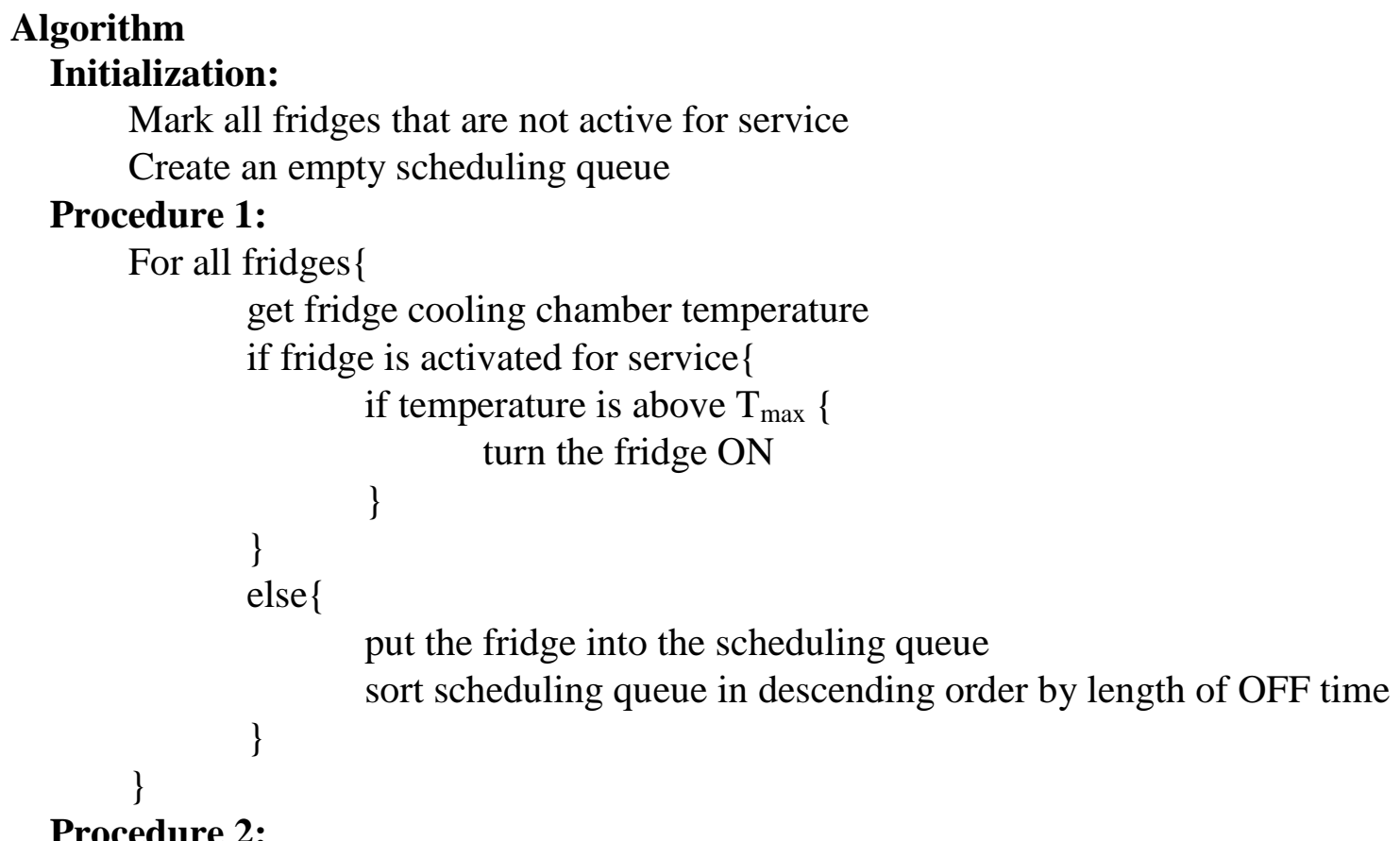

Procedure 2:

If aggregated power is higher than the set-point \{ calculate the power reduction required while power reduction is positive \{ get the first fridge from the scheduling queue mark the fridge to be activated for service subtract the fridge power from the power reduction

\}

\}

\section{Procedure 3:}

If aggregated power is lower than the set-point \{ calculate the power addition required while power addition is positive \{

get the first fridge from the activated scheduling queue mark the fridge to be deactivated from service subtract the fridge power from the power addition

\}

\}

Algorithm 1.Aggregated power control algorithm.

The controller receives temperature measurements from the fridges at two-minute intervals and the power measurements at 10-second intervals. As the model described in [22]requires the temperatures 
of the previous heating cycle and cooling cycle, the control software stores those temperature values corresponding to previous cycles (heating and cooling) locally. The heating and cooling cycles were identified by the compressor power consumption. During cooling the compressor is active and consumes power; during heating, there is no power consumption by the compressor. Some of the fridges have a power consumption of a few watts for their internal electronic components and for light bulb illumination while the fridge door is open. A $30 \mathrm{~W}$ threshold is used to separate the compressor power consumption from the power consumption by the light bulb and other components.

The aggregated power is calculated every time the power measurement from the refrigerators is updated. If the aggregated power is higher than the set limit, the coolest refrigerator among the active refrigerators is switched OFF. The procedure continues until the aggregated power reaches the control set-point. On the other hand, if the aggregated power is less than the control set-point, the hottest refrigerator among the group of controlled refrigerators is switched $\mathrm{ON}$ and the procedure continues until the aggregated power reaches the control set-point.

\subsection{Control task timings}

The temperature measurement from each fridge is received at two-minute intervals. The switch-OFF time for the active fridges (in which the compressor is ON) is calculated using the fridge model [22] every time the temperature is updated. The fridges are sorted in an order based on their switch-OFF time; the fridge that would otherwise turn off soonest would be the first priority. Although the fridge power is measured every 10 seconds, there is a time delay of 10 seconds when sensing a change in power from the fridges. When the aggregated power is limited to the reference value, the fridges which have to be switched OFF are marked internally in the software. The switch-OFF command is sent to the fridge every time, while the corresponding fridge's power measurement is received. If the temperature of the fridge reaches its Tmax, then the corresponding fridge is removed from the control list. 


\section{Experimental results}

The experiment was conducted for 24 hours for each scenario. After the experiment for one scenario, 24 hours' relaxation time was allowed for the refrigerators to return to their normal thermostatic cycles before conducting the experiment for the next scenario. Twenty-five refrigerators participated in the experiment. The maximum aggregated compressor capacity of the refrigerators is $2500 \mathrm{~W}$.

The aggregated power consumption of refrigerators in scenario 1 without control is shown in of Figure 4(a) and the instantaneous temperature average of refrigerators is shown in Figure 4(b).
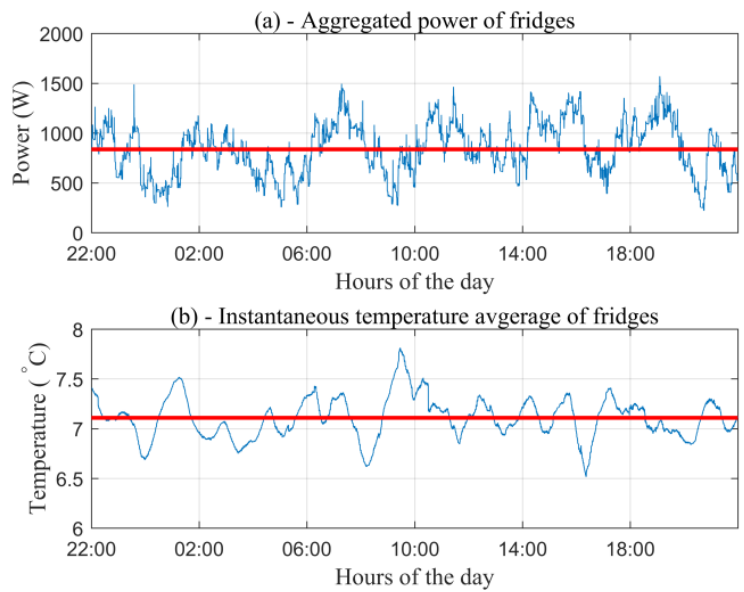

Figure 4. Aggregated power and instantaneous temperature average - Scenario 1
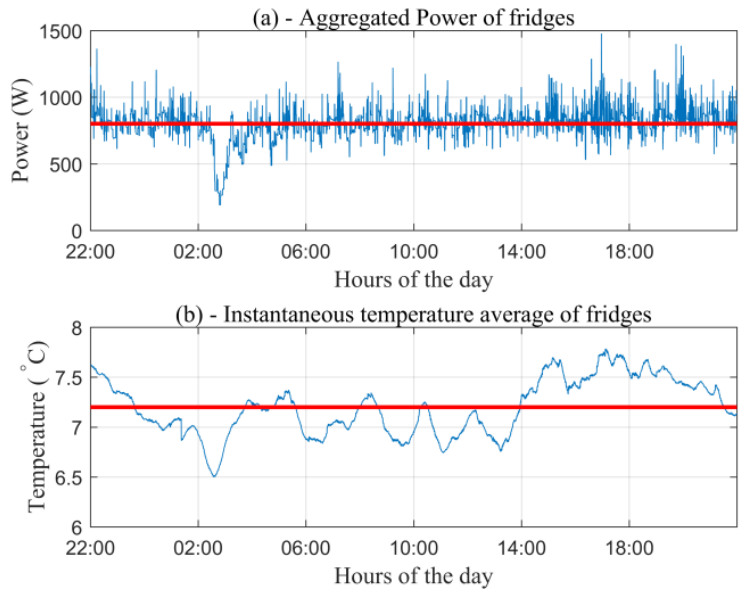

Figure 5. Aggregated power and instantaneous temperature average - Scenario 2

Their average values are marked on the respective plots as a red line. The average value of the 
aggregated power consumption of the refrigerators is $836 \mathrm{~W}$. The average value of the instantaneous temperature average is $7.1{ }^{\circ} \mathrm{C}$. The maximum value of the aggregated power is $1575 \mathrm{~W}$. Therefore the experiment for scenario 2 is conducted with the power limit set at a value of $800 \mathrm{~W}$ for the controller. The power limit value is close to $50 \%$ of the maximum power value $(1575 \mathrm{~W})$ and close to the average value $(836 \mathrm{~W})$ of scenario 1 . The aggregated power consumption of the refrigerators in scenario 2 is shown in Figure 5(a). The instantaneous temperature average of the refrigerator is shown in of Figure 5(b). Their average values are marked as a red line on the respective plots. The average value of the aggregated power is $801 \mathrm{~W}$ and the average value of the instantaneous temperature average is $7.2^{\circ} \mathrm{C}$.
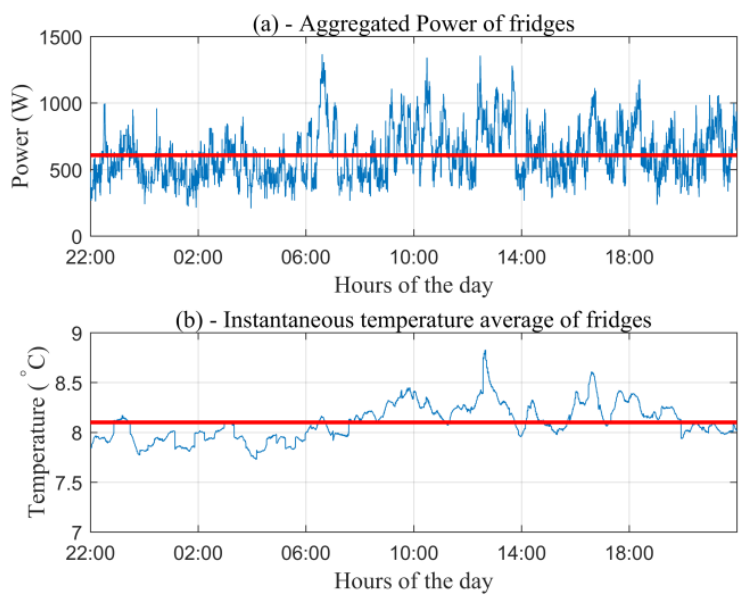

Figure 6. Aggregated power and instantaneous temperature average - Scenario 3

The experiments for scenarios 3 and 4 help to understand the change in flexibility of the overall population of refrigerators participating in the experiment. The experiment for Scenario 3 is conducted with a power limit value of $400 \mathrm{~W}$ for the controller. Similarly the experiment for Scenario 4 is conducted with a power limit value of $200 \mathrm{~W}$ for the controller. The aggregated power consumption for scenario 3 is shown in Figure 6(a). The instantaneous temperature average is shown in Figure 6(b).The power average and average of instantaneous temperature average are marked as a red line on the respective plots. The average value of the aggregated power value for scenario 3 is $607 \mathrm{~W}$ and the 
average value of the instantaneous temperature average is $8.1^{\circ} \mathrm{C}$.
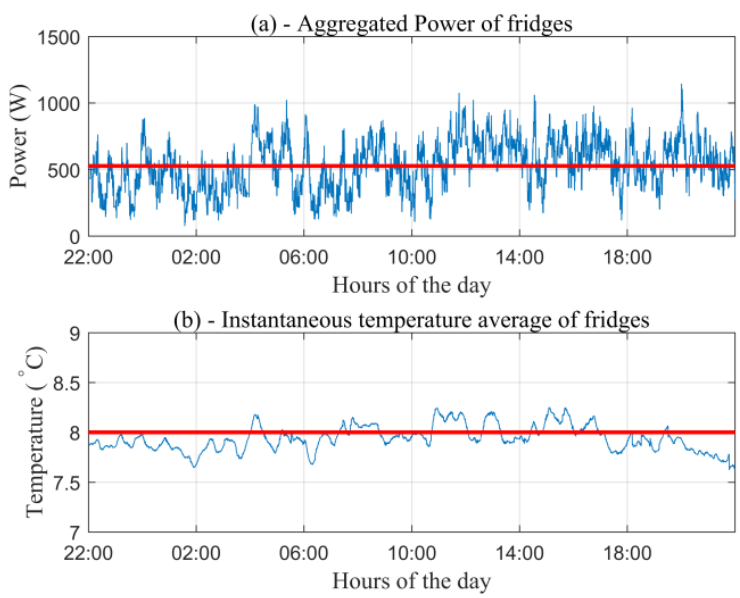

Figure 7.Aggregated power and instantaneous temperature average - Scenario 4

Similarly, the aggregated power consumption for scenario 4 is shown in Figure 7(a). The average aggregated power consumption for scenario 4 is $526 \mathrm{~W}$. The instantaneous temperature average is shown in Figure 7(b). The average value of the instantaneous temperature average is $8.0{ }^{\circ} \mathrm{C}$. The experimental results of the four scenarios are summarized in Table 1 . The overall energy consumption for scenario 1 is $20.1 \mathrm{kWh}$ and that for scenario 2 is $19.2 \mathrm{kWh}$. The difference in energy consumption is only $4.5 \%$, taking scenario 1 as the base. In scenario 2 , the controller maintains the aggregated power close to the average value of the aggregated consumption in scenario 1 , which is the normal consumption. In scenario 3 , when the power reduction is $50 \%$, the overall average temperature of the population increases by $14 \%$. The overall temperature average of the population is $8.1{ }^{\circ} \mathrm{C}$. Although the controller aims to maintain the aggregated power at close to $50 \%(400 \mathrm{~W})$ of the average consumption of scenario 1 , the achieved average aggregated power value is $73 \%(607 \mathrm{~W})$. This is due to one of the control constraints: that the temperature of every individual refrigerator must not exceed its Tmax value. The objective of conducting the experiment for scenario 4 is to understand the maximum limit of power reduction without violating the temperature conditions of the individual refrigerator of the population. The controller is provided with an objective power set-point value of 
$200 \mathrm{~W}$, which is close to $25 \%$ of the average power consumption in scenario 1 ( $836 \mathrm{~W})$. The achievable average power reduction in scenario 4 is $37 \%$ instead of $75 \%$. The average aggregated power consumption in scenario 4 is $526 \mathrm{~W}$. The temperature elevation is $13 \%$ and the average temperature of the population is $8.0^{\circ} \mathrm{C}$.

Table 1.Effect of control on the aggregated power of the refrigerators.

\begin{tabular}{|c|c|c|c|c|c|}
\hline Scenario & $\begin{array}{c}\text { Power } \\
\text { reduction } \\
{[\%]}\end{array}$ & $\begin{array}{c}\text { Power } \\
\text { limit } \\
{[\mathrm{W}]}\end{array}$ & $\begin{array}{c}\text { Average } \\
\text { temperature } \\
{\left[{ }^{\circ} \mathrm{C}\right]}\end{array}$ & $\begin{array}{c}\text { Average } \\
\text { power } \\
{[\mathrm{W}]}\end{array}$ & $\begin{array}{c}\text { Energy } \\
\text { consumption } \\
{[\mathrm{kWh}]}\end{array}$ \\
\hline 1 & $\mathrm{NA}$ & - & 7.1 & 836 & 20.1 \\
\hline 2 & $\mathrm{P}_{\mathrm{avg}}$ & 800 & 7.2 & 801 & 19.2 \\
\hline 3 & $\begin{array}{c}50 \% \text { of } \\
\mathrm{P}_{\mathrm{avg}}\end{array}$ & 400 & 8.1 & 607 & 14.6 \\
\hline 4 & $\begin{array}{c}25 \% \text { of } \\
\mathrm{P}_{\mathrm{avg}}\end{array}$ & 200 & 8.0 & 526 & 12.6 \\
\hline
\end{tabular}

Figure 8(a) shows the average value of the aggregated power of refrigerators for every 15 minutes in scenario 3. Similarly the plot for scenario 4 is shown inFigure $8(\mathrm{~b})$. The controller set-point is marked as a red line in both plots. The controller is able to limit the aggregated power consumption up to 02:00 hours in the case of scenario 3. The synchronized thermostatic operation of the refrigerators starts from 02:00 hours, as most of the refrigerators reach their maximum temperature limit. Therefore, the controller was not able to limit the aggregated power after 02:00 hours. Similarly, in scenario 4, the refrigerators reach their maximum temperature limit much earlier, in less than 2 hours (at 23:45 hours), as the controller set-point is much lower. The hours of controllability are circled in green on both plots in Figure 8. Due to the synchronization of temperature cycles, as the temperature of all refrigerators reaches the maximum, the refrigerators are switched $\mathrm{ON}$ at the same time. Their aggregated power consumption increases, which is unavoidable. When the temperature of the refrigerators decreases, the refrigerators are switched OFF until the aggregated power limit set by the controller is reached. 

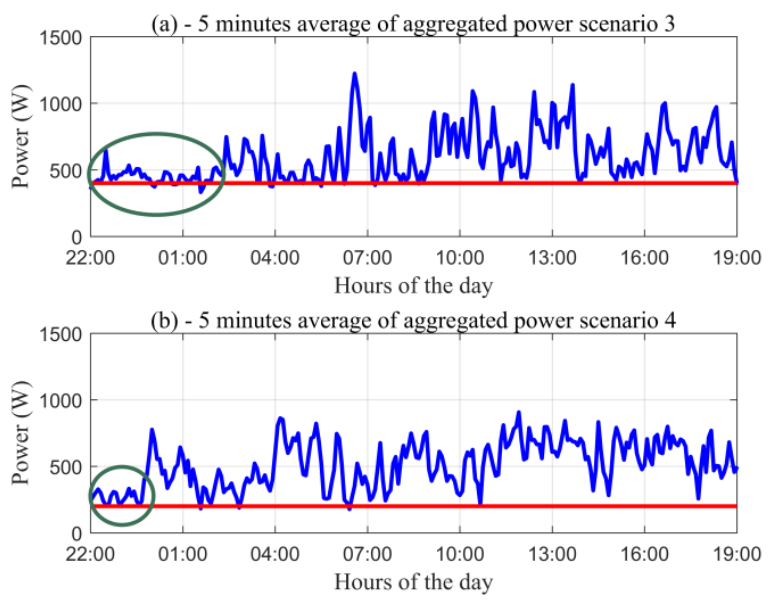

Figure 8. Aggregated power plotted with 15-minute average values for scenarios 3 and 4.

The histograms of the four experimental scenarios are shown in Figure 9. The histograms show the occurrences of aggregated power values as a probability distribution function (PDF) in the given range from 0 to $1600 \mathrm{~W}$ along with the mean value and the standard distribution. In scenario 1 , the distribution is even around the mean value and the standard deviation is high. Scenario 2 has more occurrences around the mean, and the standard deviation decreases. The mean value is also close to the controller set-point $(800 \mathrm{~W})$. When control is enabled to reduce aggregated power consumption by $50 \%$ in scenario 3 , the number of occurrences close to the controller set-point value (400 W) increases, but the standard deviation increases in comparison to scenario 2 . The mean value is higher than the controller set-point value. Similarly, in scenario 4, the standard deviation increases and the occurrences around the mean value are evenly distributed. In both scenario 3 and scenario 4 , the average power consumption is higher than the controller set-point. This is due to the synchronization of the refrigerators' temperature cycles, as shown in Figure 8. As the controller set-point of scenario 4 is lower than that of scenario 3, a greater number of refrigerators are switched OFF in scenario 4 and consequently the overall average of the aggregated power consumption is low in scenario 4 . This is visible on the histogram of the aggregated power consumption of scenario 4 . The number of occurrences of aggregated power below $600 \mathrm{~W}$ is higher for scenario 4 than for scenario 3 . 

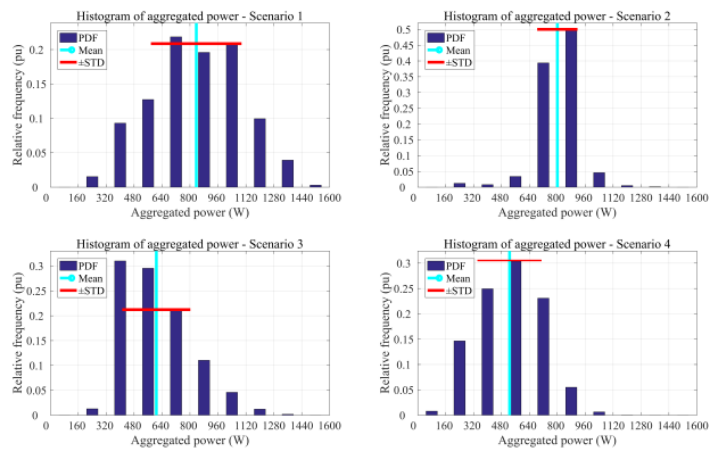

Figure 9. Histograms of the aggregated power in four scenarios.

\section{Discussion}

\subsection{Definition and quantitation of flexibility}

As the refrigerators' operations are controlled by thermostats, the refrigerator compressor will be switched OFF as soon as the temperature of the refrigerator reaches Tmin. Once the refrigerator compressor is switched OFF, the refrigerator is not available for control until the thermostat switches the compressor $\mathrm{ON}$ after the temperature reaches the limit Tmax. Thus, any refrigerator is available for control only during the cooling part of the thermostatic cycle, as shown in Figure 10.

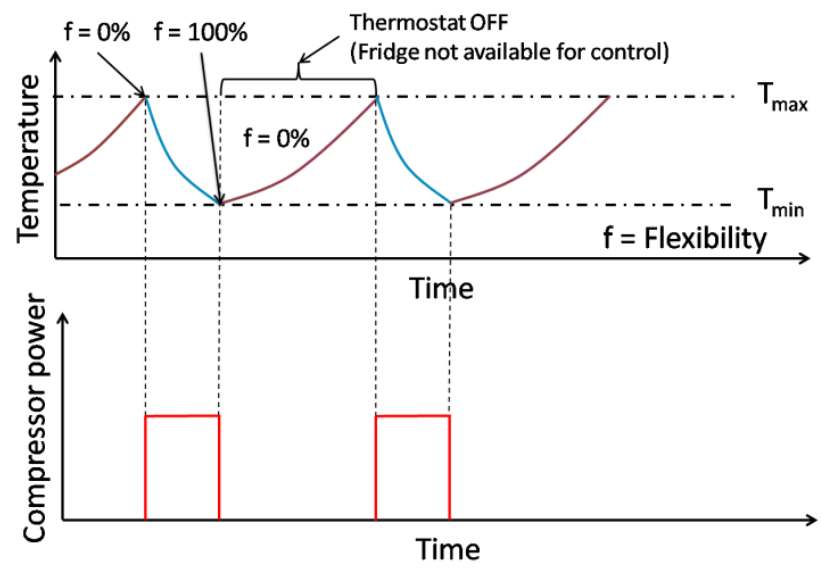

Figure 10. Flexibility change during natural thermostatic cycle.

At the beginning of the cooling, when the temperature is near Tmax, the flexibility is $0 \%$. At the end of the cooling, when the temperature is close to Tmin, the flexibility is $100 \%$ as the refrigerator can support the maximum duration of control. All of the above statements about flexibility are valid only 
when the compressor is ON. If the compressor is switched OFF by the thermostat, then the refrigerator is not available for control anymore. Therefore, the refrigerators that are switched OFF by the thermostat are considered to have no flexibility.
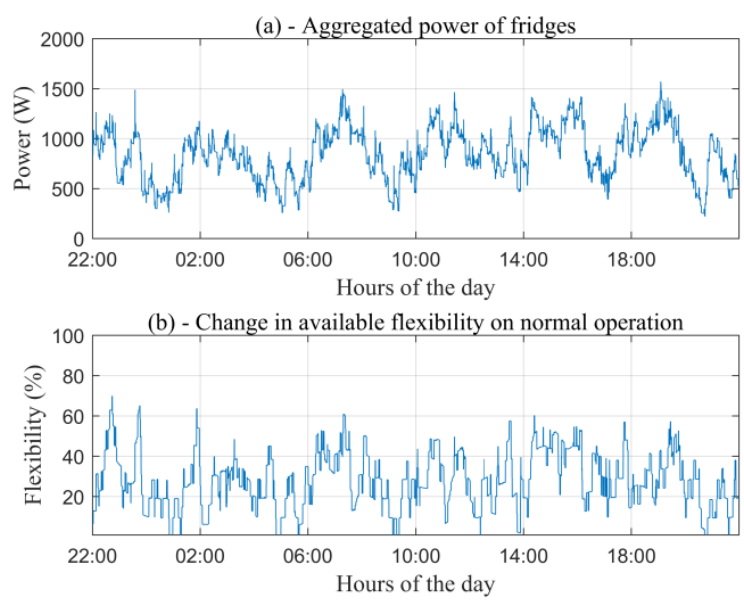

Figure 11. Change in available capacity without control

\subsection{Impact on flexibility}

Figure 11(b) shows the variation in the flexibility during normal consumption without control. The aggregated consumption is shown in Figure 11(a). It is interesting to notice that the aggregated power and the flexibility of the population follow a similar trend. A scatter plot of the aggregated power consumption versus flexibility is shown in Figure 12. As the power consumption increases, a greater number of refrigerators become available for control and the flexibility also increases. The coefficient of the correlation is 0.68 . The overall average flexibility of the population of refrigerators is $28 \%$. Table 2 summarizes the achieved average power consumption, average temperature, and quantized flexibility as percentages for the four different scenarios. The change in the flexibility during different levels of power reduction is shown in Figure 13. The change in the flexibility for scenario 2 is shown in Figure 13(a). The overall average of the flexibility for scenario 2 is $43 \%$. 


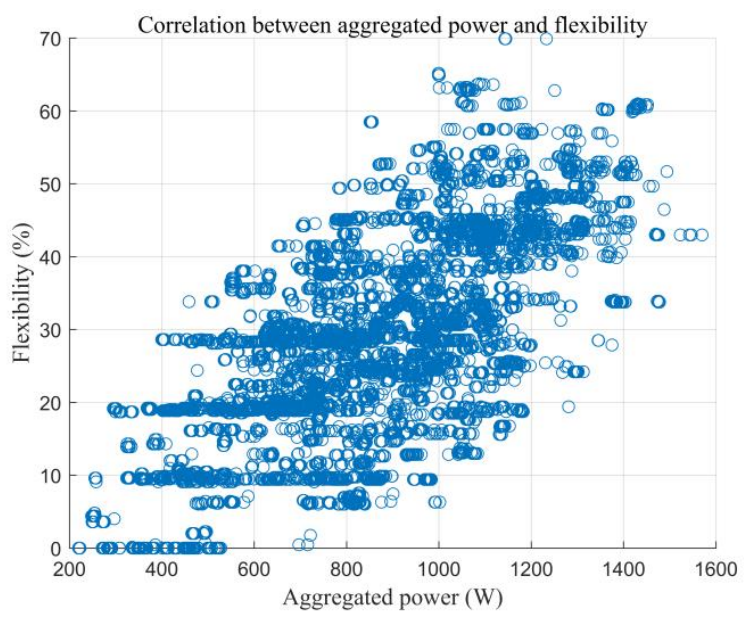

Figure 12. Correlation between aggregated power and flexibility

Table 2. Change in flexibility in different control scenarios.

\begin{tabular}{|c|c|c|c|c|}
\hline Scenario & $\begin{array}{c}\text { Power } \\
\text { limit } \\
{[\mathrm{W}]}\end{array}$ & $\begin{array}{c}\text { Achieved } \\
\text { average power } \\
{[\mathrm{W}]}\end{array}$ & $\begin{array}{c}\text { Average } \\
\text { temperature } \\
{\left[{ }^{\circ} \mathrm{C}\right]}\end{array}$ & $\begin{array}{c}\text { Available } \\
\text { flexibility } \\
{[\%]}\end{array}$ \\
\hline 1 & - & 836 & 7.1 & 28 \\
\hline 2 & 800 & 801 & 7.2 & 43 \\
\hline 3 & 400 & 607 & 8.1 & 10 \\
\hline 4 & 200 & 526 & 8.0 & 5 \\
\hline
\end{tabular}

In scenario 2, the controller maintains the aggregated power close to the average value of the aggregated consumption in scenario 1 , and the flexibility of the population increases from $28 \%$ to $43 \%$. Therefore, flexibility in scenario 2 increases by $54 \%$ compared to the base case, scenario 1 . This phenomenon is due to the control of a greater number of refrigerators to maintain the aggregated power close to the set value. The flexibility of a refrigerator is available when it is switched OFF by the controller, since it can be switched ON again if needed. On the contrary, in scenario 1 , the flexibility becomes unavailable when the refrigerator is switched OFF by the internal thermostat as shown in Figure 10.The overall average temperature of the population increases by $1 \%$ in scenario 2 in comparison with scenario 1 . In scenario 3 , when the power reduction is $50 \%$, the flexibility decreases by $64 \%$ in comparison with scenario 1 . The flexibility of the population is $10 \%$. The 
flexibility of the population decreases to $5 \%$ in scenario 4 , which can be considered as a residual capacity which cannot be utilized further. The residual capacity is due to the minimum switch-off time requirement of the refrigerator in order to avoid compressor damage due to fast switching and the high in-rush current during start-up.
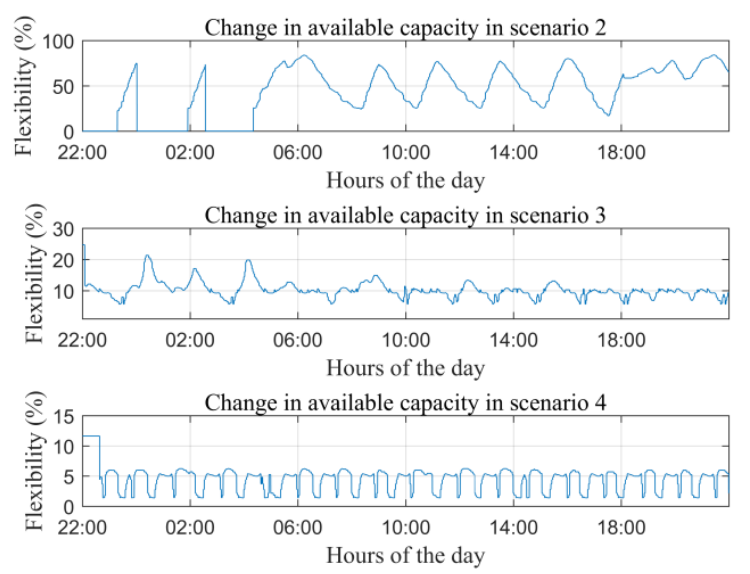

Figure 13. Change in available capacity with different power reductions.

\section{Conclusions and future work}

This paper studied the impact of DR activation on TCL flexibility variation with different levels of power reduction through a field experiment using refrigerators as an example case. The normal operation of refrigerators shows large variations in power consumption. The flexibility available with the refrigerators under normal operation is $28 \%$. Due to the natural thermostatic cycles, half of the population is not available for control. The flexibility available with the population of refrigerators in terms of flexibility increases by $54 \%$ when the refrigerators are controlled for the average aggregated consumption. Therefore, if the aggregator has direct access to the compressor control, an average flexibility of $50 \%$ is possible. When the refrigerators are controlled to reduce their power to $50 \%$ of their average consumption, as seen in scenario 1, the overall average temperature of the population increases by $14 \%$ and the flexibility decreases to $10 \%$. If the aggregated consumption is reduced by $75 \%$, due to the temperature limit restriction, the maximum possible reduction is $37 \%$. This causes the 
maximum reduction in the flexibility: to the value of $5 \%$.It will be interesting to carry out a further study by changing the selection criteria of the refrigerator. The controller ability for refrigerator selection can be modified by considering the available watt-hour capacity of individual refrigerators or by considering the available percentage flexibility of the individual refrigerator instead of making a selection based on the length of the switch-OFF time. The new resource selection strategy may improve the performance by avoiding refrigerator synchronization.

\section{Acknowledgements}

The authors would like to thank the Danish Council for Strategic Research for funding the INCAP project and other associated partners for their cooperation.

\section{References}

[1] AlRashidi, M.R., and EL-Naggar, K.M., "Long term electric load forecasting based on particle swarm optimization,” Applied Energy, Vol. 87, No. 1, pp. 320-326, January 2010.

[2] Felice, M. D., and Catalano, A.A. F., "Seasonal climate forecasts for medium-term electricity demand forecasting," Applied Energy, Vol. 137, pp. 435-444, January 2015.

[3] Ghadikolaei, H. M., Tajik, E.,Aghaei, J., andCharwand, M., "Integrated day-ahead and hourahead operation model of discos in retail electricity markets considering DGs and CO2 emission penalty cost,” Applied Energy, Vol. 95, pp. 174-185, July 2012.

[4] Amjady, N., and Keynia, F., "A new spinning reserve requirement forecast method for deregulated electricity markets," Applied Energy, Vol. 87, No. 6, pp. 1870-1879, June 2010.

[5] EnergiNet.dk, Grid Code 3.2.3 Power Unit above 1,5 MW, December 2009.

[6] Ozer, B., Arikan, O., Moral, G., and Altintas, A., "Extraction of primary and secondary frequency control from active power generation data of power plants," International Journal of Electrical Power \& Energy Systems, Vol. 73, pp. 16-22, December 2015.

[7] Marinelli, M., Sossan, F., Costanzo, G. T., and Bindner, H. W., "Testing of a predictive control strategy for balancing renewable sources in a microgrid," Sustainable Energy, IEEE Transactions on, Vol. 5, No. 4, pp. 1426-1433, October 2014. 
[8] Keyaerts, N.,Delarue, E.,Rombauts, Y.,and D'haeseleer, W., "Impact of unpredictable renewables on gas-balancing design in Europe,” Applied Energy, Vol. 119, pp. 266-277, April 2014.

[9] Vidal-Amaro, J. J., Østergaard, P. A.,and Sheinbaum-Pardo, C., “Optimal energy mix for transitioning from fossil fuels to renewable energy sources - The case of the Mexican electricity system,” Applied Energy, Vol. 150, pp. 80-96, July 2015.

[10] Stötzer, M., Hauer, I., Richter, M., andStyczynski, Z. A., "Potential of demand side integration to maximize use of renewable energy sources in Germany," Applied Energy, Vol. 146, pp. 344-352, 15 May 2015.

[11] National Institute of Standards and Technology, "NIST framework and roadmap for smart grid interoperability standards, release 2.0," Special Publ. 1108R2, p. 218, February2012.

[12] Lorna A. G., "Demand response resources: who is responsible for implementation in a deregulated market?," Energy, Vol. 35, pp. 1518-1525, April 2010.

[13] Huang, Y., Tian, H., and Wang, L., "Demand response for home energy management system," International Journal of Electrical Power \& Energy Systems, Vol. 73, pp. 448-455, December 2015 .

[14] Aalami, H.,Yousefi, G. R.,Moghadam, M.P., "Demand Response model considering EDRP and TOU programs," IEEE/PES Transmission and Distribution Conference and Exposition, 2008, Vol. 1, No. 6, pp. 21-24, April 2008.

[15] Hoeven, M. V., "Nordic energy technology perspectives: pathways to a carbon neutral energy future," 2013 Nordic Energy Technology Perspectives OECD/IEA. Technical Report 2013.

[16] He H., Borhan M. S., Kameshwar P., Tyrone L. V., "Potentials and economics of residential thermal loads providing regulation reserve," Energy Policy, vol. 79, pp. 115-126, April 2015

[17] Bondy, D. E. M., Costanzo, G. T., Heussen, K., and Bindner, H, W. "Performance assessment of aggregation control services for demand response," IEEE PES Innovative Smart Grid Technologies Conference Europe (ISGT-Europe), Vol. 1, No. 6, pp. 12-15, October 2014.

[18] Kwon, P. S., and Østergaard, P., “Assessment and evaluation of flexible demand in a Danish future energy scenario,” Applied Energy, Vol. 134, pp. 309-320, December 2014.

[19] Niro, G., Salles, D., Alcântara, M. V. P., and Da Silva, L. C. P., "Large-scale control of domestic refrigerators for demand peak reduction in distribution systems," Electric Power Systems Research, Vol. 100, pp. 34-42, July 2013. 
[20] Kremers, E., Durana, J. M. G. D., and Barambones, O., "Emergent synchronisation properties of a refrigerator demand side management system," Applied Energy, Vol. 101, pp. 709-717, January 2013.

[21] Sossan, F., Lakshmanan, V., Costanzo, G. T., Marinelli, M., Douglass, P. J., and Bindner, H. W., "Grey-box modelling of a household refrigeration unit for energy consumption prediction and optimization using time series data," Sustainable Energy, Grids and Networks, Vol. 5, 2016, pp. 1-12.

[22] Lakshmanan, V., Marinelli, M., Kosek, A. M., Sossan, F., and Norgard, P., "Domestic refrigerators temperature prediction strategy for the evaluation of the expected power consumption," Proc. 2013 Innovative Smart Grid Technologies Europe (ISGT EUROPE 2013) 4th IEEE/PES,pp. 1-5, October 2013.

[23] Lakshmanan, V., Gudmand-Høyer, K., Marinelli, M., Kosek, A. M., and Nørgård, P., "Energy shift estimation of demand response activation on refrigerators - A field test study," Proc. 49th International Universities' Power Engineering Conference UPEC2014, pp. 1-5, September 2014. 